\title{
Veinticuatro años de la acción de nulidad de laudos: un análisis empírico
}

\author{
Xavier Andrade Cadena* \\ Gabriela Rivadeneira Chacón** \\ Carolina Arroyo Aguirre *** \\ Estefanía Fierro Valle**** \\ Sol González Vallejo*****
}

Recibido/Received: 23/08/2021

Aceptado/Accepted: 11/10/2021

SumARIO: 1. Introducción y resumen de los hallazgos. 2. La muestra de la investigación. 3. Los hallazgos. 3.1 Los árbitros son buenos guardianes del debido proceso. 3.2 La acción de nulidad es una extensión del litigio principal propiciada por el demandado. 3.3. Las incongruencias extra y ultra petita son las causales preferidas de los accionantes. 3.4 Otras causas disfrazadas de incongruencias son una importante causa de anulación de laudos arbitrales. 3.5. La mayoría de las causales son resueltas de forma adecuada. 3.6. Los laudos pueden ser anulados por la Corte Constitucional por causales distintas a las de la LAM cuando se trate de vulneración de derechos constitucionales. 3.7 Las accio-

\footnotetext{
* Socio de la firma AVL Abogados; profesor de la Universidad San Francisco de Quito; abogado y doctor en jurisprudencia por la Pontificia Universidad Católica del Ecuador; LL.M. por McGill University; M.A. in Economics por el King's College London.

** Asociada de la firma AVL Abogados, Abogada por la Universidad San Francisco de Quito; Máster en Litigio y Arbitraje Internacional por la Universidad San Francisco de Quito; Máster en Fiscalidad Internacional por la Universidad Internacional de la Rioja; candidata a la Maestría en Derecho con mención en Planificación Tributaria y Fiscalidad Internacional por la Universidad Andina Simón Bolívar.

*** Asociada Senior de la firma AVL Abogados; profesora de la Universidad San Francisco de Quito, L.L.B B.A. en Administración de Empresas por la Universidad San Francisco de Quito, MLB. por Bucerius Law School, WHU Otto Beisheim School of Management.

**** Asociada Senior de la firma AVL Abogados, Abogada por la Universidad San Francisco de Quito; Máster en Derecho por la Universidad de McGill; Diploma in EU Competition Law por el King's College London.

***** Abogada por la Universidad San Francisco de Quito.
} 
nes de nulidad son resueltas extemporáneamente. 3.8 Otros hallazgos. 4. Consideraciones previas sobre la acción de nulidad. 5. Análisis cuantitativo. 5.1. ¿Cuántas acciones de nulidad han sido presentadas a nivel nacional? 5.2. ¿Quiénes inician las acciones de nulidad? 5.3. ¿Cuáles son las causales más invocadas? 5.4 ¿Cuáles son las causales más aceptadas por las cortes provinciales? 5.5 ¿Cuánto tarda en resolverse una acción de nulidad en Ecuador? 5.6. ¿Quiénes son demandados en una acción de nulidad? 5.7. Correlación con número de procesos arbitrales presentados en los distintos Centros y las acciones de nulidad iniciadas. 6. Análisis Cualitativo. 6.1. Casual a). 6.2. Casual b). 6.3 Casual c). 6.4. Casual d). 6.5. Casual e). 6.6 ¿Se ha declarado la nulidad de un laudo arbitral por causales no contempladas en el artículo 31 de la LAM? 7. Conclusiones.

Resumen: Este artículo realiza un análisis cualitativo y cuantitativo de las acciones de nulidad de laudos arbitrales presentadas en Ecuador desde la promulgación de la Ley de Arbitraje y Mediación en el 1997, con el objetivo de contrastar las normas legales con la práctica judicial. Esta aproximación nos ha permitido detectar los aciertos y las falencias de las resoluciones de las cortes provinciales sobre la acción de nulidad.

Palabras Clave: arbitraje, acción de nulidad, laudos arbitrales.

\section{Twenty-four years annulment action of awards: an empirical analysis}

Aвstract: This article undertakes a qualitative and quantitative analysis of the setting aside applications against arbitral awards brought in Ecuador since the enactment of the Arbitration and Mediation Law in 1997, with the aim of confronting the law with the courts' practice. This approach has allowed us to identify the strengths and shortcomings of the decisions of the provincial courts on the actions for setting aside awards.

KeYWORDS: arbitration, annulment, awards. 


\section{INTRODUCCIÓN Y RESUMEN DE LOS HALLAZGOS}

La acción de nulidad es un punto de inflexión para el arbitraje. Es la frontera procesal donde lo privado se encuentra con lo público. Si la acción de nulidad no es bien administrada por las cortes estatales, las bondades del arbitraje se desvanecen, pues de poco sirve obtener un laudo jurídicamente sólido, dictado por árbitros idóneos, en tiempos razonables, si luego es anulado erróneamente por las cortes. Bien administrada, la acción de nulidad es un medio efectivo de tutela de los derechos de las partes procesales, especialmente del debido proceso y el derecho a la defensa.

Existe extensa doctrina nacional y comparada sobre la acción de nulidad, por lo que este artículo no pretende ahondar sobre los estudios doctrinarios existentes. En contraste, pretende demostrar empíricamente los efectos reales de la acción de nulidad desde la expedición de la Ley de Arbitraje y Mediación (en adelante la "LAM") en 1997. Esta aproximación nos permitirá desmitificar ciertos temores sobre asuntos que son menos relevantes de lo que pensábamos -y que son objeto de intensos debates académicos- y alertar sobre otros que tienen la capacidad de desnaturalizar a la acción de nulidad si no son corregidos a tiempo.

Para tal efecto, luego de explicar la muestra analizada en este estudio (sección 2), explicaremos los principales hallazgos acompañados de las interpretaciones de los autores (sección 3). Después de contextualizar a la acción de nulidad (sección 4), emprenderemos un análisis cuantitativo (sección 5) y cualitativo (sección 6) de dicha acción, para finalmente alcanzar ciertas conclusiones (sección 7).

\section{LA MUESTRA}

La muestra de este estudio consiste en 259 sentencias judiciales que resuelven acciones de nulidad de laudos arbitrales expedidas a nivel nacional en los últimos 20 años (desde 2001 hasta el 2020). Utilizamos dos fuentes: (i) todas las sentencias disponibles en el Sistema Automático de Trámite Judicial Ecuatoriano (en adelante 
"SATJE") y (ii) ciertos expedientes físicos a los que hemos tenido acceso. La muestra es estadísticamente significativa porque considera el $100 \%$ de sentencias que pueden obtenerse en el SATJE².

\section{Los HALlAzgos}

En el proceso de investigación tratamos de identificar varias correlaciones (i.e. relación lineal y proporcional entre dos variables) considerando diversos elementos y datos de las sentencias dictadas en procesos de nulidad. Hemos descartado varias correlaciones, dejando solo aquellas que son lógica y estadísticamente plausibles. A continuación resumimos los principales hallazgos encontrados.

\subsection{Los árbitros son buenos guardianes del debido proceso}

Se estima que entre el $10 \%$ de los laudos arbitrales son impugnados vía acción de nulidad. Este porcentaje no es preciso porque no existen cifras oficiales ni públicas del universo de procesos arbitrales que han concluido en Ecuador a partir de la expedición de la LAM. Adicionalmente, la información de los centros que administran arbitrajes es limitada y se desconoce el número de procesos ad hoc.

En todo caso, se estima que, de todas las acciones de nulidad propuestas, solo el $9 \%$ son aceptadas; es decir, apenas el 1\% total de laudos arbitrales son finalmente anulados.

Estos porcentajes no son preocupantes y se encontrarían acordes con la media mundial ${ }^{3}$, lo cual nos lleva a pensar que la

1. El Sistema Automático de Trámite Judicial Ecuatoriano se implementó a partir del año 2011, después del referéndum de 7 de mayo de 2011 y del estado de excepción de la Función Judicial mediante el decreto 874 de 5 de septiembre de 2011. Este sistema registra y permite realizar un seguimiento en tiempo real de las actividades desarrolladas en cada una de las causas de todas las judicaturas a nivel nacional.

2. Esto no quiere decir, sin embargo, que el $100 \%$ de sentencias de nulidad hayan sido consideradas, pues enfrentamos varios obstáculos en la recolección de los datos, entre ellos, (i) el SATJE fue implementado a partir del 2011 y antes de ello no era posible hacer búsquedas por tipo de acción; (ii) podrían existir potenciales errores en la categorización de la información por parte del SATJE; y (iii) casos no actualizados, no digitalizados, entre otros errores del SATJE y de quienes lo alimentan.

3. Con el objetivo de comparar el porcentaje de anulación de laudos arbitrales en Ecuador se ha investigado el porcentaje de anulación de laudos en los principales Centros de Arbitraje del 
acción de nulidad, en principio, no constituye un peligro real para el sistema arbitral, como en ocasiones se propone en círculos académicos y profesionales. Esto se debe, en gran medida, a que las cortes provinciales han sabido contener los intentos de las partes procesales de volver a la acción de nulidad una instancia más de litigio. No obstante, existe el riesgo de que esta realidad cambie si las cortes provinciales continúan interpretando ciertas causales de manera errónea, como comentaremos más adelante.

Estos números también indican que los árbitros, en su contundente mayoría, son buenos guardianes del debido proceso. El hecho de que solo el 1\% de los laudos sean anulados es una muestra inequívoca de que los árbitros rara vez incurren en errores in procedendo. En consecuencia, no debe quedar duda de que en el sistema arbitral las garantías procesales y constitucionales son celosamente resguardadas.

\subsection{La acción de nulidad es una extensión del litigio principal propiciada por el demandado}

El 75\% de las acciones de nulidad son propuestas por quien fue demandado en el arbitraje y solo el $25 \%$ por el actor.

Estos porcentajes permiten intuir que los demandados encontrarían en la acción de nulidad una oportunidad para continuar litigando el caso y retardar la ejecución de la decisión. Esta es la única explicación plausible que encontramos, pues sería irrazonable pensar que las violaciones al debido proceso, sobre las que versan las causales de nulidad, perjudican en su gran mayoría a la parte demandada $(75 \%)$ y en menos medida a la parte actora $(25 \%)$.

La estrategia del demandado, sin embargo, se ve seriamente truncada por el efecto devolutivo (no suspensivo) de la acción de

mundo y en varias jurisdicciones. A continuación, se resumen los porcentajes de anulación de laudos arbitrales:

- Según las estadísticas de la Cámara de Comercio Internacional, desde el año 2015 hasta el año 2019 se han presentado 223 acciones de nulidad y únicamente se han aceptado 27 acciones.

- $\quad$ En el caso del CIADI, la anulación de laudos tiene un enfoque más restrictivo. Entre el 2001 y el 2010 las estadísticas evidencian que el porcentaje de anulación fue del 13\%, mientras que en el período de 2011 a 2020 el porcentaje de anulabilidad de laudos fue del 3.1\%. 
nulidad, pues el laudo puede ser ejecutado a menos de que se haya solicitado su suspensión rindiendo caución suficiente, conforme dispone el artículo 31 de la LAM. En la práctica, la suspensión es raramente solicitada por el costo disuasivo que implica presentar una caución.

A lo anterior se debe añadir que el porcentaje de éxito de una acción de nulidad, como fue explicado, es mínimo (9\%). Entonces, la aventura de demandar la nulidad de un laudo, bajo un análisis costo beneficio, es onerosa y poco prometedora, especialmente cuando el demandado conoce que su acción no tiene futuro. Retardar la agonía de la parte vencida, incurriendo en mayores costos (ej. honorarios de abogados) hasta que la corte provincial deseche la acción de nulidad en pocos meses, no es una estrategia acertada.

\subsection{Las incongruencias extra y ultra petita son las causales preferidas de los accionantes}

Del universo de sentencias analizadas, en el $44 \%$ de ellas se invocó la causal d) del artículo 31 de la LAM que se refiere a las incongruencias extra petita (i.e. resolver sobre cuestiones no sometidas a arbitraje) y ultra petita (i.e. conceder más allá de lo reclamado). Solo en Pichincha -provincia donde más casos de arbitraje existen y, correlativamente, de acciones de nulidad-casi la mitad de las acciones de nulidad se fundamentan en dicha causal. ¿Por qué esta causal es tan popular? Simple: porque los jueces se han extralimitado en sus funciones y han permitido que esta causal se convierta en un cajón de sastre. Volveremos sobre esta afirmación en el acápite siguiente.

Preocupa también que causales distintas a las previstas en el artículo 31 de la LAM sean también populares a nivel nacional y, en provincias como Guayas y Azuay, sean las segundas más invocadas. Del $100 \%$ las acciones presentadas en estas provincias, el $22 \%$ se refieren a vulneraciones al debido proceso, específicamente por la vulneración al derecho a ser juzgado por un juez competente, por violaciones al derecho a la defensa y por falta de motivación del laudo. 


\subsection{Lo más preocupante: los asuntos misceláneos, disfrazados de incongruencias extra y ultra petita, configuran la principal causal de nulidad de laudos en Ecuador}

La causal (d) del artículo 31 de la LAM (incongruencias extra y ultra petita) no le debe su popularidad a que los árbitros incurran frecuentemente en estas incongruencias, sino a que los jueces han permitido que en ella se cuele un surtido listado de causas que no tienen relación con la norma. No nos encontramos, entonces, ante el análisis de una causal definida, sino ante una serie de causales que han permitido que la acción de nulidad extienda furtivamente su alcance gracias al ingenio de los accionantes y la extralimitación de los jueces. En consecuencia, la gran demanda que tiene esta causal en el mercado no debe sorprendernos, pues, mientras más asuntos permeen en esta causal, mayor será el universo de accionantes.

En las motivaciones que han aceptado las cortes provinciales para anular laudos, mal utilizando la causal (d) del artículo 31 de la LAM, se observan dos vertientes:

Errores de derecho: por ejemplo, sobre i) la inarbitrabilidad de la disputa, especialmente sobre actos administrativos; ;ii) la interpretación de un contrato; iii) la orden de pago a favor del socio de una compañía sin que haya precedido un proceso de liquidación ${ }^{5}$; iv) la declaratoria de validez de una escritura pública sin haber estado facultado el Tribunal para ello en el convenio arbitral $^{6}$; y v) no haber imputado apropiadamente el valor de un anticipo a una deuda ${ }^{7}$.

Errores en la valoración de la prueba: por ejemplo, sobre la orden de un tribunal a pagar daños sin considerar un informe pericial ${ }^{8} \mathrm{y}$

4. Proceso 17100-2013-0042, sentencia dictada por la Corte Provincial de Pichincha el 16 de mayo de 2018; y proceso 17100-2018-00006, sentencia dictada por la Corte Provincial de Pichincha el 2 de agosto de 2018.

5. Proceso No. 17100-2018-0032, sentencia dictada por la Corte Provincial de Pichincha el 13 de febrero de 2019.

6. Proceso No. 09100-2018-00016, sentencia dictada por la Corte Provincial de Guayas el 8 de agosto de 2018.

7. Proceso No. 09100-2019-00013, sentencia dictada por la Corte Provincial de Guayas el 17 de septiembre de 2019.

8. Proceso No. 17113, 2014, 1296, sentencia dictada por la Corte Provincial de Pichincha el $10 \mathrm{de}$ octubre de 2014. 
ii) la falta de valoración de una prueba que habría dejado al actor en indefensión?".

Del 100\% de laudos anulados bajo la causal bajo análisis, estimamos que la mitad se refieren realmente a las incongruencias extra y ultra petita. Esta conclusión es alarmante porque ello implicaría que, en realidad, una de las principales causales para anular laudos en Ecuador -a la que podemos denominar la causal "misceláneos"- no se encuentra prevista en la ley.

Esta realidad inquieta, no solo porque los jueces se han extralimitado en la aplicación de la LAM, sino porque la causal "misceláneos" se refiere mayormente a asuntos de fondo sobre los cuales no tienen competencia las cortes provinciales, como ellas mismas lo han advertido ${ }^{10}$.

El actuar de las cortes provinciales está supeditado al marco jurídico ecuatoriano, lo cual implica que se ven compelidas, por un lado, a admitir a trámite únicamente las causales previstas taxativamente en el artículo 31 de la LAM y, por otro lado, a rechazar de plano toda causal que se refiera a la aplicación del derecho y a la valoración de las pruebas, pues las partes del convenio arbitral le han otorgado esa facultad, de manera exclusiva y excluyente, a los árbitros.

Especial mención merecen los casos donde, con el pretexto de analizar la causal (d), las cortes provinciales han entrado a analizar la arbitrabilidad de la materia sometida al arbitraje, cuando esta valoración es una prerrogativa exclusiva de los árbitros ${ }^{11}$. El artículo 22 de la LAM determina que los árbitros resolverán su propia

9. Proceso No. 09100-2014-0166, sentencia dictada por la Corte Provincial de Guayas el 9 de diciembre de 2014.

10. Proceso No. 17100-2015-00003, sentencia dictada por la Corte Provincial de Pichincha el 17 de noviembre de 2015: "[...] sin que sea competencia de esta Autoridad el revisar el fondo de tal pronunciamiento, puesto que como ya se manifestó, la acción de nulidad de laudo arbitral no es una vía para acceder a una instancia que revise integralmente la controversia resuelta por el laudo...".

Véanse también los siguientes procesos: Proceso No. 17100-2018-00027, sentencia dictada por la Corte Provincial de Pichincha el 6 de mayo de 2019; No. 17100-2019-00003, sentencia dictada por la Corte Provincial de Pichincha el 15 de mayo de 2019; Proceso No. 09100-2014-0005, sentencia dictada por la Corte Provincial de Guayas el 18 de febrero de 2014.

11. En otras legislaciones esta prerrogativa es compartida con los jueces cuando una de las causales de nulidad de un laudo es la inarbitrabilidad de la materia o por razones de orden público. En Ecuador tales causales no existen. 
competencia en virtud del principio kompetenz-kompetenz, para lo cual deberán necesariamente examinar si la materia que conocen es transigible o no. Realizar este análisis de manera ex post, por parte de un órgano judicial que carece de competencia, despojando a los árbitros de sus facultades y sin norma que lo permita, implica una violación a la garantía constitucional del debido proceso ${ }^{12}$.

Parecería innecesario explicar en qué consisten las inconsistencias extra y ultra petita de las que trata la causal (d) del artículo 31 de la LAM-las mismas cortes provinciales se han encargado de hacerlo con claridad $^{13}-\mathrm{y}$ por qué estas inconsistencias no tienen relación alguna con la arbitrabilidad de las controversias. Bastaría por resaltar que mientras las primeras exigen un examen de errores in procedendo de competencia exclusiva de las cortes provinciales, la segunda implica un examen in iudicando de competencia exclusiva de los árbitros.

\subsection{El resto de las causales, en la mayoría de los casos, son resueltas de manera apropiada}

La resolución de las demás causales de nulidad se realiza de manera adecuada por las cortes provinciales debido a que los jueces se basan en exámenes adecuados para que proceda cada causal, alcanzando cierta predictibilidad sobre el alcance de las causales de nulidad y su aplicación en la práctica.

12. Constitución de la República, artículo 76(7)(k): "Ser juzgado por una jueza o juez...competente". Véase también la Sentencia No. 1737-16-EP/21 de 21 de julio de 2021: "Es decir, al que le correspondia pronunciarse sobre el convenio arbitral es al tribunal arbitral, mas no a la justicia ordinaria, ya que, según el principio kompetenz kompetenz, el tribunal arbitral es el primero en resolver sobre su competencia. Por lo que, el análisis sobre la suficiencia y validez de la cláusula arbitral y, por ende, la determinación de si la cláusula arbitral era o no patológica o si el tribunal arbitral era competente o no para conocer la controversia, es un asunto que no le correspondía a la justicia ordinaria".

13. Proceso No. 17100-2018-00006, sentencia dictada por la Corte Provincial de Pichincha el 2 de agosto de 2018: "La incongruencia se produce cuando la porción dispositiva del laudo ha incorrectamente considerado la dinámica entre pretensiones y excepciones respecto de su contenido y ha fallado sobre asuntos distintos o mayores a los restringidamente resultantes de la interacción de esas pretensiones o excepciones. La incongruencia es un error in procedendo que tiene tres aspectos: a) Cuando se otorga más de lo pedido (plus o ultra petita); b) Cuando se otorga algo distinto a lo pedido (extra petita); y, e) Cuando se deja de resolver sobre algo pedido (citra petita o infra petita). Entonces como instrumento de análisis, el defecto procesal de incongruencia debe resultar de la comparación entre la súplica de la demanda, la contestación y la parte dispositiva de la sentencia".

Véanse también los siguientes procesos: Proceso No. 17100-2014-0059, sentencia dictada por la Corte Provincial de Pichincha el 7 de enero de 2016; proceso No. 17100-2018-00029, sentencia dictada por la Corte Provincial de Pichincha el 3 de diciembre de 2018. 


\subsection{Loslaudos pueden seranulados por la Corte Constitucional por causales distintas a las previstas en la LAM cuando estas configuren violaciones constitucionales}

En el año 2019 la Corte Constitucional emitió dos sentencias en las que se refirió a la necesidad de agotar la acción de nulidad previo a iniciar una acción extraordinaria de protección, evitando así que esta última sea desnaturalizada.

La Corte Constitucional enfatizó en dichas sentencias que la acción de nulidad es "un medio de impugnación extraordinario por errores in procedendo en el arbitraje y vicios de extra petita en la decisión, relacionados al debido proceso arbitral y establecidos taxativamente..." 14 . Este medio extraordinario no puede interponerse a menos de que verse sobre una vulneración de derechos que no esté concebida como causal de nulidad en la LAM ${ }^{15}$. En la práctica, esta posibilidad es limitada, pues las causales de nulidad de la LAM salvaguardan ampliamente el derecho constitucional a la defensa de las partes.

\subsection{Las acciones de nulidad son resueltas extemporáneamente}

El artículo 31 de la LAM dispone que las cortes provinciales deberán resolver la acción de nulidad "dentro del término de treinta días contados desde la fecha que avocó conocimiento de la causa". Si bien el término previsto por el legislador parecería ser apretado, no podemos dejar de mencionar que esta disposición ha sido ampliamente ignorada.

\subsection{Otros hallazgos}

Este artículo contiene otros hallazgos que arrojan los datos de las sentencias estudiadas, entre otros, si los árbitros son demandados en las acciones de nulidad.

14. Corte Constitucional, Sentencia No. 31-14-EP/19 de 19 de noviembre de 2019.

15. Corte Constitucional, Sentencia No. 31-14-EP/19 de 19 de noviembre de 2019: "En consecuencia, por las consideraciones expuestas, esta Corte Constitucional determina que las causales establecidas expresamente en el artículo 31 de la LAM deben ser agotadas cuando la vulneración que se pretende alegar en la acción extraordinaria de protección se enmarque en una de ellas. Sin que ello signifique que otras vulneraciones que no encuentren sustento en la acción de nulidad puedan ser presentadas de forma directa ante esta Corte a fin de que estas tengan una tutela constitucional que las garantice". 


\section{Consideraciones PREVIAS}

La acción de nulidad de un laudo arbitral es una acción contemplada en el artículo 31 de la LAM que tiene por objeto anular un laudo por las razones expresamente previstas en dicho artículo. Se trata de una acción autónoma -no un recurso vertical-que puede ser presentado por cualquiera de las partes procesales.

La acción de nulidad debe interponerse ante tribunal arbitral que dictó el laudo en el término de 10 días contados desde la fecha de ejecutoría del laudo ${ }^{16}$. La parte que interpone la acción de nulidad puede solicitar la suspensión de la ejecución del laudo, rindiendo caución suficiente sobre los perjuicios estimados que la demora en la ejecución del laudo podría causar a la otra parte. El árbitro o tribunal arbitral, en el término de 3 días, debe fijar el monto de la caución, disponiendo la suspensión de la ejecución del laudo si esta es rendida ${ }^{17}$.

El tribunal arbitral debe remitir el proceso al presidente de la Corte Provincial del lugar en donde fue dictado el laudo, quien deberá verificar si la acción fue interpuesta dentro del término. De ser así, el presidente de la Corte Provincial pondrá la acción de nulidad en conocimiento de la contraparte para que la conteste dentro de un término de 5 días ${ }^{18}$. De lo contrario, inadmitirá la acción de nulidad.

En una sentencia del año 2020, la Corte Constitucional señaló que quien debe determinar si la acción de nulidad fue presentada dentro del término es el tribunal arbitral.

La acción de nulidad conforme el ordenamiento jurídico debe ser presentada ante el árbitro o tribunal arbitral para que este pueda calificar su oportunidad. En caso de ser oportuna, remitirá el proceso al presidente de la Corte Provincial respectivo. Contrario sensu, los árbitros deberán declarar la extemporaneidad de la acción y tenerla como no interpuesta, pues debe procurarse una oportuna y consecuente ejecución del laudo arbitral conforme a la ley una vez que ha fenecido el

16. Artículo 1, Reglas a aplicarse en el trámite de acción de nulidad de laudo arbitral, Resolución de la Corte Nacional de Justicia 8, Registro Oficial 983 de 12 de abril de 2017.

17. Artículo 31, Ley de Arbitraje y Mediación.

18. Artículo 1, Reglas a aplicarse en el trámite de acción de nulidad de laudo arbitral, Resolución de la Corte Nacional de Justicia 8, Registro Oficial 983 de 12 de abril de 2017. 
término para interponer la única acción legal que se puede interponer contra este con potencialidad de suspender sus efectos ${ }^{19}$.

El presidente de la Corte Provincial debe resolver la acción de nulidad dentro del término de treinta días contados desde la fecha que avocó conocimiento de la causa, luego convocará a las partes a una audiencia para que presenten sus posiciones. En dicha audiencia se practicarán las pruebas que hubieren sido anunciadas al proponer la acción de nulidad ${ }^{20} \mathrm{y}$ se dictará la sentencia de manera oral y motivada ${ }^{21}$.

No se podrán interponer recursos en contra de la sentencia que dicte el presidente de la corte provincial respecto de la acción de nulidad de laudo ${ }^{22}$.

\section{Análisis cuantitativo}

En esta sección se realizará un análisis cuantitativo sobre el número de acciones de nulidad de laudos arbitrales [5.1]; el porcentaje de las acciones iniciadas por los actores o demandados [5.2]; las causales de nulidad más invocadas [5.3]; las causales de nulidad más aceptadas por las cortes provinciales [5.4]; el tiempo aproximado de resolución de una acción de nulidad [5.5]; análisis respecto de quiénes han sido los sujetos de las acciones de nulidad en la práctica [5.6]; y se analizará la correlación entre los arbitrajes administrados por los principales centros de arbitraje del país y el número de acciones de nulidad iniciados anualmente [5.7].

\section{1. ¿Cuántas acciones de nulidad han sido presentadas a nivel nacional?}

Desde el año 2001 hasta la fecha de cierre de esta investigación, el número de acciones de nulidad presentados por año ha sido diverso. Los años en que más acciones se han presentado fueron

19. Corte Constitucional, Sentencia No 308-14-EP/20 de 19 de agosto de 2020.

20. Artículo 1, Reglas a aplicarse en el trámite de acción de nulidad de laudo arbitral, Resolución de la Corte Nacional de Justicia 8, Registro Oficial 983 de 12 de abril de 2017.

21. Artículo 3, Reglas a aplicarse en el trámite de acción de nulidad de laudo arbitral, Resolución de la Corte Nacional de Justicia 8, Registro Oficial 983 de 12 de abril de 2017.

Ver también, Artículo 79, Código Orgánico General de Procesos.

22. Artículo 4, Reglas a aplicarse en el trámite de acción de nulidad de laudo arbitral, Resolución de la Corte Nacional de Justicia 8, Registro Oficial 983 de 12 de abril de 2017. 
2014, 2017, 2018, 2019 y 2020 tal como se detalla en el gráfico que consta a continuación:

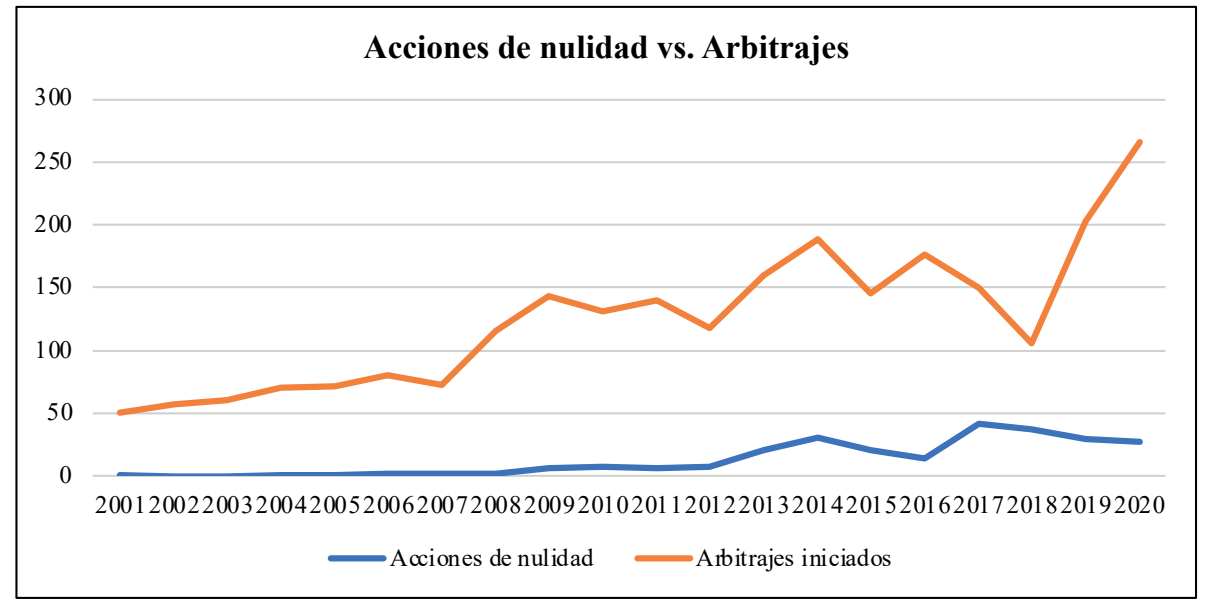

El aumento en el número de las acciones de nulidad iniciados parecería guardar cierta relación proporcional con el aumento de arbitrajes por año. Sin embargo, por las limitaciones dela información disponible, no es posible atribuir conclusiones inequívocas.

\section{2. ¿Quiénes inician las acciones de nulidad?}

Del análisis realizado se desprende que en la mayoría de los casos son los demandados en el proceso arbitral quienes recurren a la acción de nulidad:

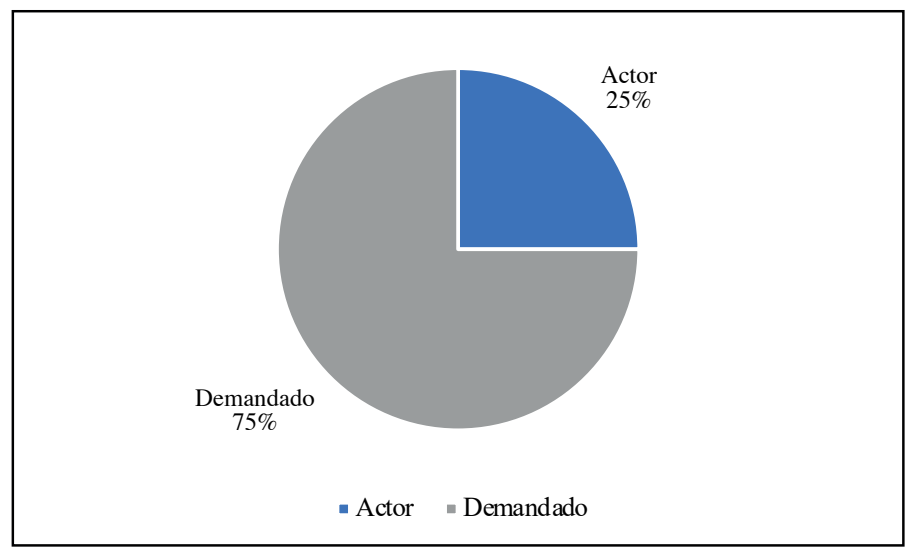


El 75\% de las acciones de nulidad presentadas a nivel nacional corresponde a las partes que actuaron en calidad de demandados en el arbitraje. Esto demuestra que la acción de nulidad tiene más relación con la intención del demandado de retardar la ejecución del laudo, que con la impugnación de la decisión arbitral por motivos procesales genuinos.

\section{3. ¿Cuáles son las causales más invocadas?}

De las acciones de nulidad analizadas para la provincia de Pichincha, para las cuales ya existe una sentencia disponible que permita conocer las causales invocadas por la parte accionante, se desprende que la causal d) es la causal más invocada, seguida de la causal c). El porcentaje de veces que fueron invocadas estas causales ya sea de manera independiente o conjunta, se muestra a continuación:

\section{Causales más invocadas en Pichincha}

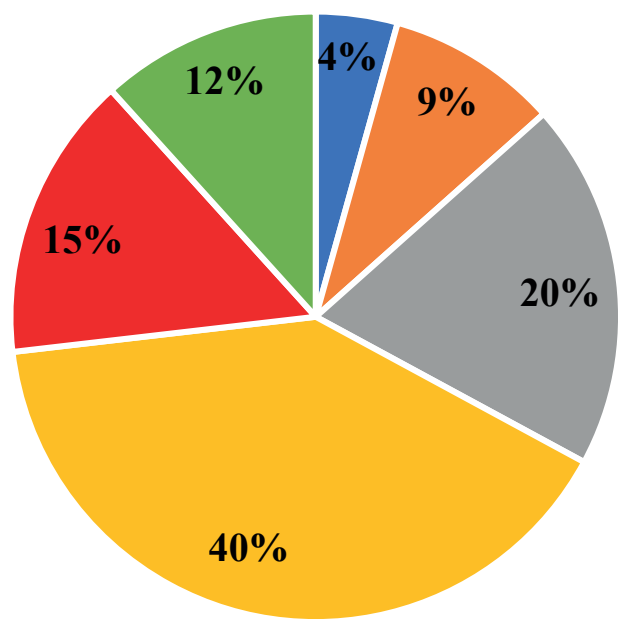

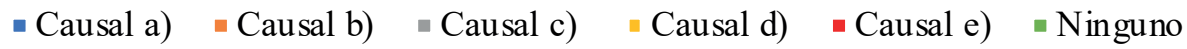


Las "otras causales" invocadas están relacionadas con vulneraciones del derecho al debido proceso, la emisión del laudo fuera del plazo, así como la vulneración al derecho de petición.

En el caso de la Provincia del Guayas, de las 63 acciones de nulidad resueltas se desprende que la causal más invocada es la causal d) con un $38 \%{ }^{23}$. Sin embargo, en el $23 \%$ de las acciones analizadas, fueron invocadas otras causales no previstas en la LAM. El porcentaje de veces que fueron invocadas las causales ya sea de manera independiente o conjunta se muestra a continuación:

\section{Causales más invocadas en Guayas}

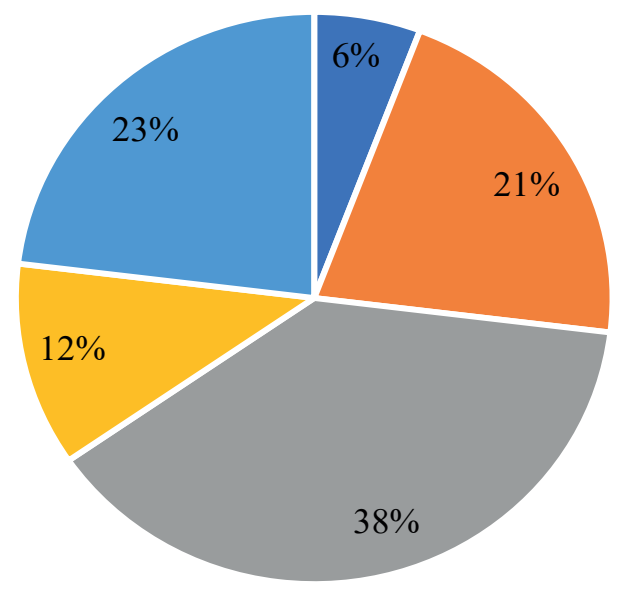

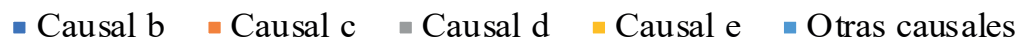

Entre las "otras causales" invocadas por la parte accionante se encuentran: i) haber transgredido el derecho de petición de una de las partes; ii) falta de motivación del laudo; iii) violación al debido proceso; iv) "motivación absurda" del laudo; y v) la vulneración al derecho de ser juzgado por un juez imparcial y competente.

En los casos resueltos por la presidencia de la Corte Provincial del Azuay, en el $40 \%$ de las 5 acciones de nulidad resueltas se invocó

23. En provincias como Tungurahua o Manabí, no ha sido posible identificar las acciones. 
la causal d); en un $20 \%$ la causal e); en el $20 \%$ la causal c); y en un $20 \%$ la falta de motivación del laudo, como se muestra en el siguiente gráfico:

\section{Causales más invocadas en Azuay}

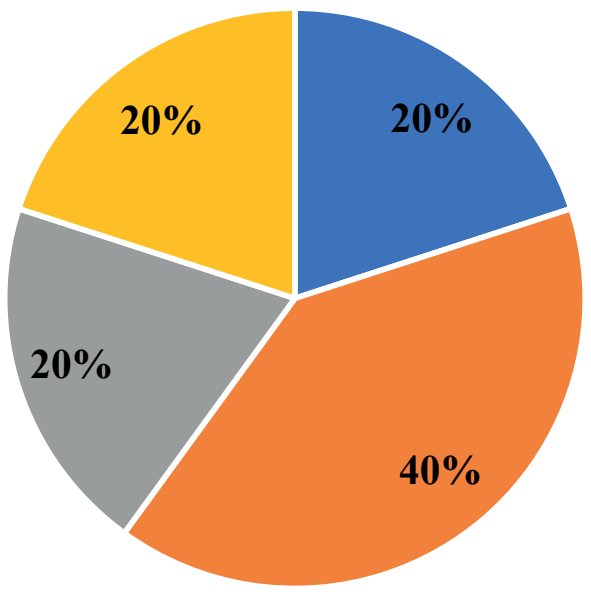

- Causal c) $₫$ Causal d) $\backsim$ Causal e) $₫$ Otras causales

\section{4. ¿Cuáles son las causales más aceptadas por las cortes provinciales?}

En las provincias de Pichincha y Guayas, que son estadísticamente las más representativas, la causal más invocada y además más aceptada por la presidencia de la Corte Provincial fue la d).

\section{5. ¿Cuánto tarda en resolverse una acción de nulidad en Ecuador?}

El artículo 31 de la LAM establece que las acciones de nulidad deben ser resueltas en el término de 30 días desde que la presidencia de la Corte Provincial avoca conocimiento de la causa. Pese a esto, en la práctica, las acciones de nulidad en el Ecuador no son resueltas en este término. 
Hasta la presente fecha se han resuelto 188 acciones de nulidad desde la promulgación de la LAM. El 53\% de ellas son resueltas dentro de los 6 meses desde su presentación; existen un número ínfimo de casos en los que la acción de nulidad fue resuelta dentro de los 30 días previstos en la LAM. Asimismo, como se puede observar en el gráfico; el 24\% de las acciones han sido resueltas entre los 6 y 12 meses; el 9\% de los casos en 12 a 18 meses; el 8\% en 12 a 24 meses. Solamente el 7\% de las acciones de nulidad son resueltas en más de 24 meses.

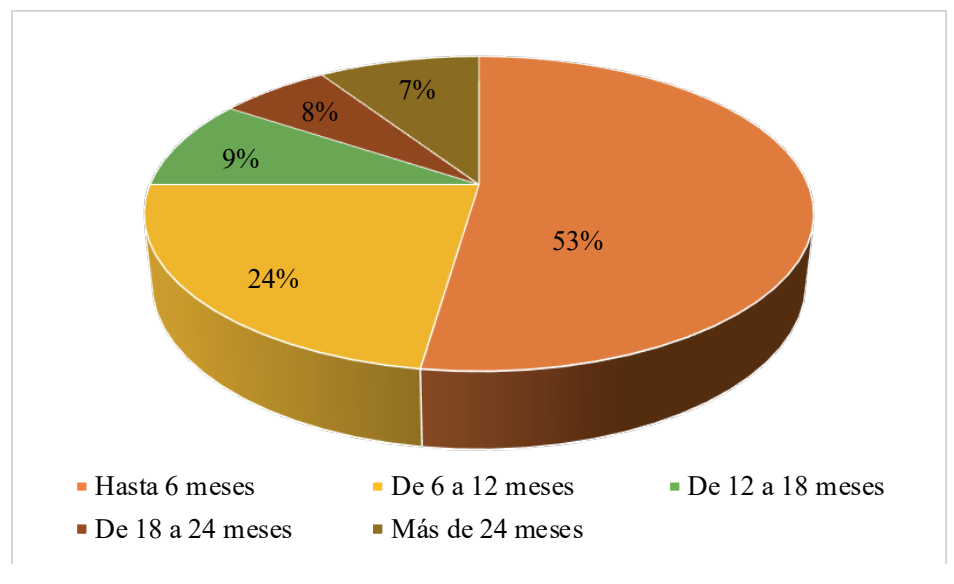

Esta tendencia se mantiene en cada una de las cortes provinciales a nivel nacional. Como se demuestra en el siguiente gráfico, las acciones de nulidad son resueltas mayoritariamente dentro de los primeros 6 meses desde su presentación.

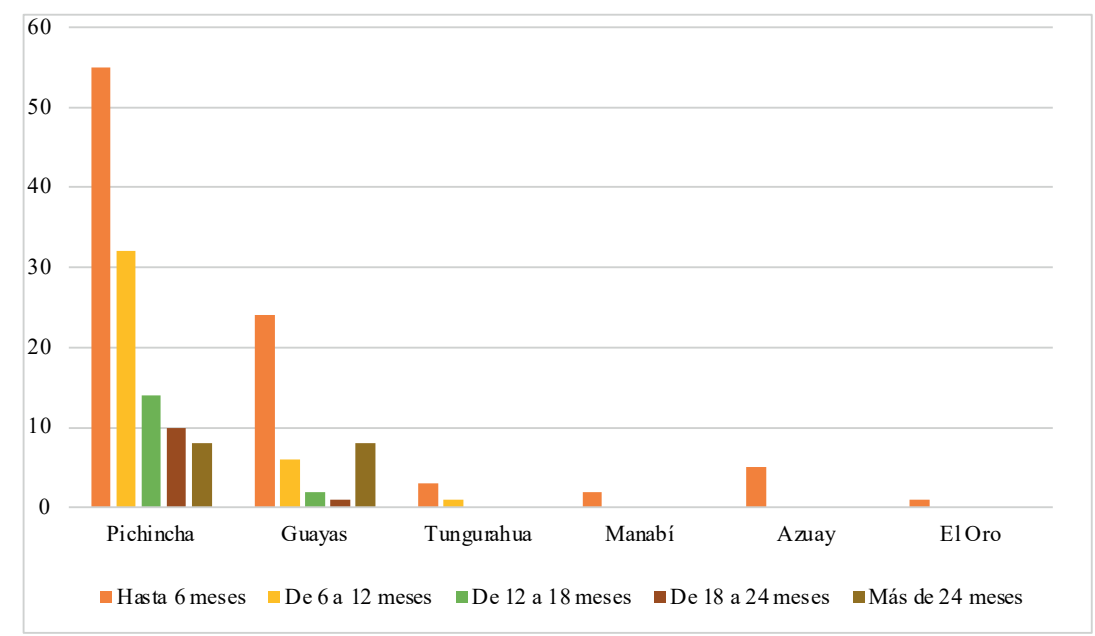




\section{6. ¿Quiénes son demandados en una acción de nulidad?}

La Corte Nacional de Justicia y las cortes provinciales se han pronunciado en numerosas ocasiones sobre la legitimación de las acciones de nulidad enfatizando que estas deben oponerse en contra de los titulares del derecho de contradicción; es decir, "en contra de quienes son los sujetos procesales del primer proceso que se ven directamente afectados por la declaratoria de nulidad en caso de producirse" 24 . Consecuentemente, el tribunal arbitral que dicta el laudo no es el llamado a contradecir una acción de nulidad.

Este criterio fue compartido por la Corte Constitucional en la sentencia No. 308-14-EP/ 20 en la que señaló que la legitimación pasiva de una acción de nulidad le corresponde a la parte del arbitraje que no interpuso la acción de nulidad y no a los árbitros o a la institución administradora del arbitraje ${ }^{25}$.

Pese a lo anterior, en los casos analizados se pudo evidenciar que en el 25\% de los casos se demandó a los árbitros que dictaron el laudo objeto de la anulación y en el $1 \%$ de casos se demandó al centro de arbitraje.

\subsection{Correlación entre el número de procesos arbitrales y de acciones de nulidad}

El porcentaje de las acciones de nulidad parecería estar estrechamente relacionado con el número de arbitrajes. A manera

24. Proceso No. 17100-0069-2008, sentencia dictada por la Corte Provincial de Pichincha el 8 de febrero de 2010.

Véase además el proceso No. 17100-2014-0068, sentencia dictada por la Corte Provincial de Pichincha el 20 de marzo de 2015.

25. Corte Constitucional, Sentencia No 308-14-EP/20 de 19 de agosto de 2020:

"A pesar de la indeterminación en la norma legal en cuanto a la legitimación pasiva, debe entenderse que la declaratoria de nulidad de un laudo arbitral puede afectar directamente a la contraparte del arbitraje, a quien ya se le confirió certeza sobre determinada controversia por la autoridad de cosa juzgada del laudo arbitral. Por lo cual, la parte procesal del arbitraje que no presentó la acción de nulidad del laudo arbitral es la llamada a contradecir la pretensión de nulidad, en tanto dicha decisión tiene la potencialidad de alterar su situación jurídica.

En este punto, cabe precisar que la titularidad de la legitimación pasiva en la acción de nulidad del laudo arbitral se limita a las partes del arbitraje y no se extiende a los árbitros o a la institución administradora del arbitraje. Estos últimos tienen la aspiración lícita de que su labor como autoridad jurisdiccional y administrativa sea reconocida, esto es, que el laudo arbitral sea declarado válido y despliegue sus naturales efectos, pero su posición no es equiparable a la de una parte procesal cuyos derechos e intereses legítimos se encuentran en juego". 
de ejemplo, hemos seleccionado los datos de dos de los principales centros de arbitraje del país con el objetivo de determinar dicha correlación:

Del análisis de los datos de: i) Centro de Arbitraje y Mediación de la Cámara de Comercio de Quito; ii) el Centro de Arbitraje y Mediación de la Cámara de Comercio Ecuatoriano Americana se desprende que, de los 2378 procesos arbitrales tramitados, se presentaron 271 acciones de nulidad; es decir, en un $11,4 \%$ de los casos.

En los gráficos que se muestran a continuación se evidencia la mencionada correlación. En el Centro de Arbitraje de la Cámara de Comercio de Quito, el porcentaje acciones de nulidad interpuestas desde el año 1997 al año 2020 es del 11\% en comparación con el número de arbitrajes:

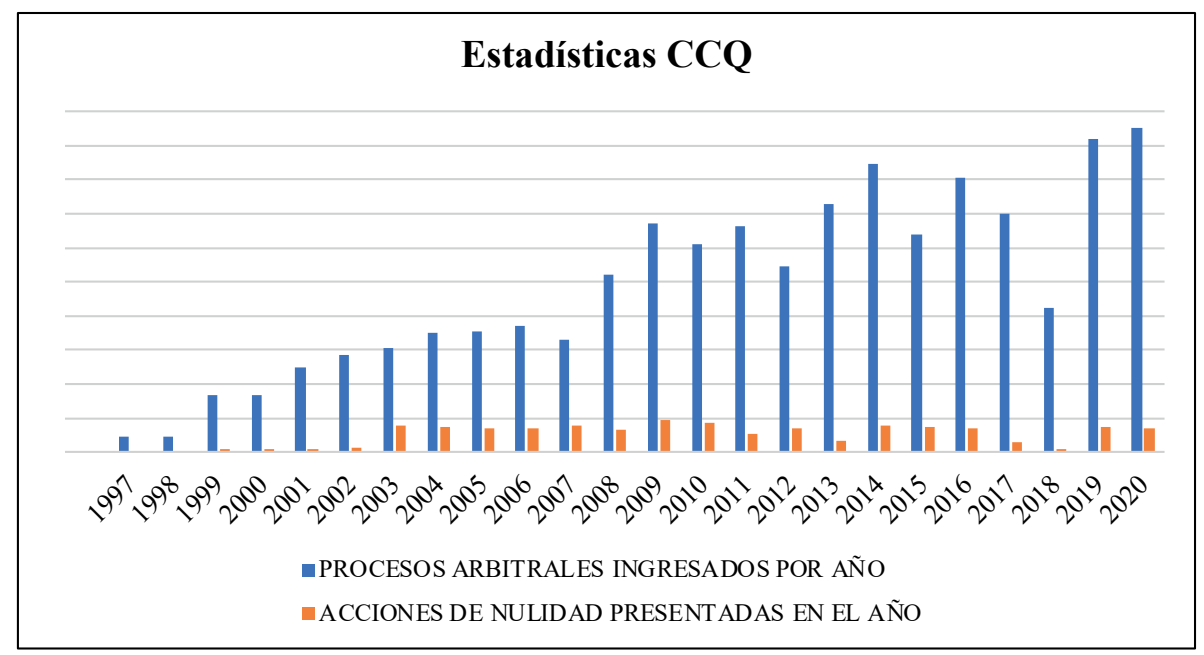

En el Centro de Arbitraje y Mediación de la Cámara de Comercio Ecuatoriano Americana, la relación entre los arbitrajes y las acciones de nulidad interpuestas en el período del 2007 y 2020 es del 19\%: 


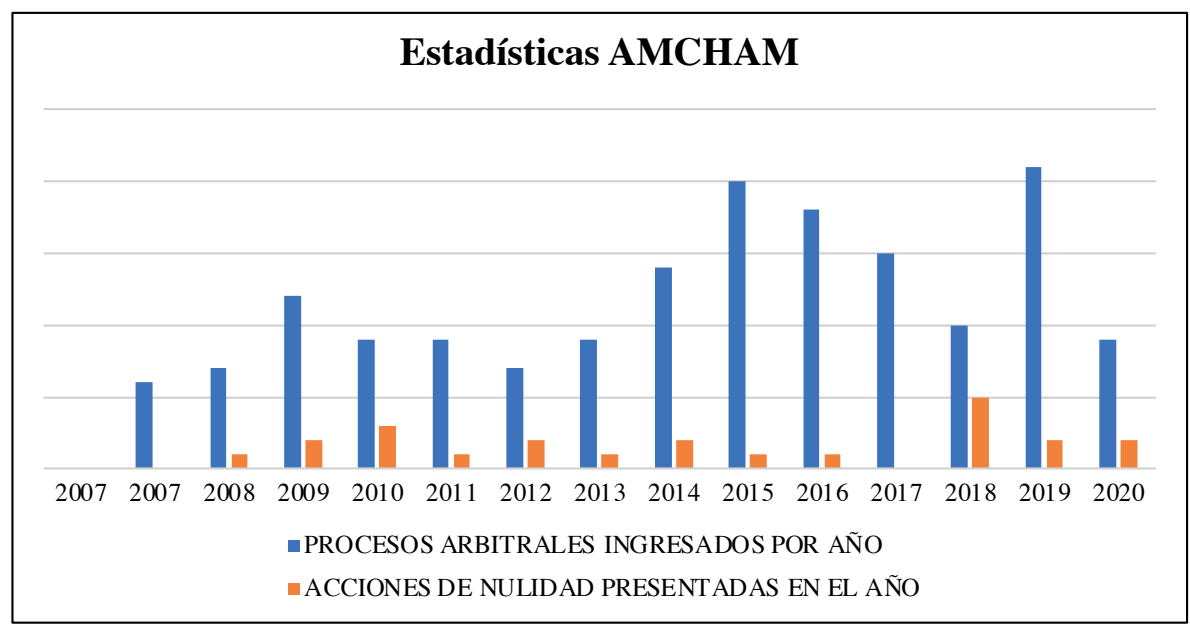

Estas estadísticas estarían acordes a la media mundial, tal como fue señalado anteriormente ${ }^{26}$.

\section{Análisis CUAlitativo}

A continuación, se expondrán los principales criterios adoptados por las presidencias de las cortes provinciales para verificar las causales de nulidad previstas en el artículo 31 de la LAM [6.1-6.5]. Finalmente, se examinarán los casos en que se han anulado laudos por una causal distinta a las previstas en el artículo 31 de la LAM [6.6].

\subsection{Causal a): que no se haya citado legalmente con la demanda y el juicio se haya seguido y terminado en rebeldía.}

La LAM exige el cumplimiento de los siguientes presupuestos para que se verifique esta primera causal:

No se haya citado legalmente con la demanda y el juicio se ha seguido y terminado en rebeldía. Será preciso que la falta de citación haya impedido que el demandado deduzca sus excepciones haga valer sus derechos $\mathrm{y}$, además, que el

26. N. 8. 
demandado reclame por tal omisión al tiempo de intervenir en la controversia.

Con el fin de determinar si esta causal se verifica, los presidentes de las cortes provinciales analizan si existe documentación que respalde la citación o que demuestre que el demandado no tuvo la oportunidad de intervenir en el proceso arbitral y oponer excepciones ${ }^{27}$.

Entonces, esta causal prosperará únicamente si se verifican de manera conjunta todas las condiciones previstas en la LAM: (i) la falta de citación al demandado o que la citación no se hubiera realizado en forma legal; (ii) que el juicio haya iniciado y terminado en rebeldía; (iii) que el demandado no haya presentado excepciones debido a la falta de citación; y (iv) que el demandado hubiere reclamado la falta de citación al intervenir en el proceso. Estos cuatro requisitos fueron resumidos a sentencia de la Corte Provincial de Pichincha:

En este orden de ideas, para invocar esta causal, el artículo 31 de la LAM establece como requisitos la concurrencia simultánea de cuatro hechos, sin los cuales la acción no podría prosperar, estos son: a) Que no se haya citado la demanda al demandado o que dicha citación no fuere legal; b) Que el juicio haya seguido y terminado en rebeldía; c) Que la falta de citación haya impedido que el demandado deduzca excepciones o haga valer sus derechos; d) Que el demandado reclame por tal omisión al tiempo de intervenir en la controversia ${ }^{28}$.

27. Proceso No. 17100-2017-00007, sentencia dictada por la Corte Provincial de Pichincha el 1 de septiembre de 2017: "Será preciso que la falta de citación haya impedido que el demandado deduzca sus excepciones o haga valer sus derechos y, además, que el demandado reclame por tal omisión al tiempo de intervenir en la controversia"; es decir, esta causal tiene por objeto que el órgano jurisdiccional anule un laudo dictado en un proceso arbitral, cuando se viole una solemnidad sustancial, de por sí insubsanable, como es la falta de citación de la demanda y por causar indefensión a la parte demandada, al no permitirle conocer su contenido y poder ejercer su derecho de defensa".

Véase también proceso No. 17100-2017-00024, sentencia dictada por la Corte Provincial de Pichincha el 17 de noviembre de 2017.

28. Proceso No. 17100-2018-00025, sentencia dictada por la Corte Provincial de Pichincha el 11 de diciembre de 2018.

Ver también proceso No. 17100-2018-00022, sentencia dictada por la Corte Provincial de Pichincha el 18 de enero de 2019; proceso No. 17100-2018-00004, sentencia dictada por la Corte Provincial de Pichincha el 13 de septiembre de 2018. 
En nuestra opinión, el análisis que los presidentes de las Cortes Provinciales realizan sobre esta causal es el adecuado, puesto que, para determinar su verificación basta determinar documentalmente si se ha citado al demandado y si este ha comparecido o no al proceso.

\subsection{Causal b): que no se haya notificado a una de las partes con las providencias del tribunal y este hecho impida o limite el derecho de defensa de la parte}

La causal contenida en la letra b) del artículo 31 de la LAM procede en los casos en los que "no se haya notificado a una de las partes con las providencias del tribunal y este hecho impida o limite el derecho de defensa de la parte".

La importancia de esta causal radica en que la notificación es una forma de comunicación entre las partes y los árbitros y, en consecuencia, permite que las partes puedan ejercer su derecho a la defensa y contradicción. En palabras del presidente de la Corte Provincial de Pichincha: "[...] resulta importante considerar que la notificación de las providencias no solo sirve como mecanismo de comunicación entre los árbitros y las partes, sino que también activa el principio de contradicción que permite al actor o al demandado exponer sus observaciones respecto al proceso arbitral que se está desarrollando" 29.

Las cortes provinciales al analizar esta causal han establecido la necesidad de que concurran tres requisitos: (i) que exista una providencia emitida por el tribunal arbitral; (ii) que la providencia no haya sido notificada a las partes; y (iii) que la falta de notificación haya afectado el derecho a la defensa de las partes ${ }^{30}$.

29. Proceso No. 17100-2018-00011, sentencia dictada por la Corte Provincial de Pichincha el 25 de octubre de 2016.

Ver también proceso No. 17100-2017-00005, sentencia dictada por la Corte Provincial de Pichincha el 19 de agosto de 2017; proceso No. 17100-2017-0006, sentencia dictada por la Corte Provincial de Pichincha el 9 de noviembre de 2017; proceso No. 17100-2017-00039, sentencia dictada por la Corte Provincial de Pichincha el 12 de abril de 2018; proceso No. 17100-20150001, sentencia dictada por la Corte Provincial de Pichincha el 13 de enero de 2016; proceso No. 17100-2019-00005, sentencia dictada por la Corte Provincial de Pichincha el 14 de agosto de 2019.

30. Proceso No. 17100-2015-00016, sentencia dictada por la Corte Provincial de Pichincha el 3 de agosto de 2016: "La causal de nulidad de la letra b) del artículo 31 de la LAM, es muy clara, para que esta opere deben confluir tres elementos fundamentales, primero, debe existir una providencia emitida por el Tribunal Arbitral, es decir, se trata de una providencia emitida una 
Al estar esta causal estrechamente relacionada con el derecho a la defensa y contradicción de las partes. La jurisprudencia ha determinado que para que proceda esta causal debe: (i) existir una providencia emitida por el tribunal arbitral que no haya sido notificada a las partes; (ii) y que debido a la falta de notificación se haya menoscabado efectivamente el derecho a la defensa.

De nuestro análisis se desprende que el control efectuado por los presidentes de las cortes provinciales es adecuado, en la medida en que la falta de notificación no implica necesariamente una vulneración al derecho al debido proceso, siendo necesario para ello verificar que efectivamente se haya vulnerado el derecho a la defensa de una de las partes.

\subsection{Causal c): cuando no se hubiere convocado, no se hubiere notificado la convocatoria, o luego de convocada no se hubiere practicado las pruebas, a pesar de la existencia de hechos que deban justificarse}

Otra de las causales de anulación consiste en la falta de notificación de la convocatoria a la práctica de pruebas o de la práctica misma de las pruebas. En este sentido, la letra c) del artículo 31 de la LAM establece que cabe la nulidad de un laudo arbitral cuando "no se hubiere convocado, no se hubiere notificado la convocatoria, o luego de convocada no se hubiere practicado las pruebas, a pesar de la existencia de hechos que deban justificarse".

En la misma línea de las demás causales, los presidentes de las cortes provinciales de justicia estudian el expediente para determinar

vez que se encuentre debidamente sorteado y posesionado dicho Tribunal; segundo, debe existir falta de notificación a una de las partes con dicha providencia, lo cual se puede verificar de la revisión de los recaudos procesales; y finalmente esta falta de notificación debe limitar el derecho a la defensa de la parte; entonces, únicamente cuando se produzcan estos tres presupuestos se puede alegar nulidad por esta causal, solo de esta forma se puede hablar de que se está afectando al derecho a la defensa, violentando el principio de contradicción, y consecuentemente, transgrediendo el debido proceso, el cual también abarca al principio de inmediación, prohíbe la indefensión y garantiza la defensa de los sujetos procesales en todas las etapas del procedimiento, conforme lo señalan los artículos 75 y 76.7. a de la Constitución de la República". Ver también proceso No. 17100-2015-00019, sentencia dictada por la Corte Provincial de Pichincha el 20 de junio de 2016; proceso No. 17100-2017-00005, sentencia dictada por la Corte Provincial de Pichincha el 19 de agosto de 2017; proceso No. 17100-2017-00039, sentencia dictada por la Corte Provincial de Pichincha el 12 de abril de 2018; proceso No. 17100-201900005, sentencia dictada por la Corte Provincial de 14 de agosto de 2019. 
si existe la convocatoria, la notificación de la convocatoria y la posterior práctica de una prueba solicitada ${ }^{31}$.

En este ejercicio, los presidentes de las cortes provinciales parten de la premisa de que la prueba es una "actividad/etapa necesaria que implica demostrar la verdad de un hecho ocurrido, su existencia o contenido según sea el caso" ${ }^{\prime \prime 2}$.

La jurisprudencia ha sido enfática en que esta causal no puede ser invocada con el fin de que el presidente de la corte provincial se pronuncie sobre la forma en que se practicó la prueba y mucho menos sobre la valoración que hubiere realizado el tribunal arbitral sobre ella ${ }^{33}$.

Adicionalmente, en un caso basado en esta causal, se ha establecido que, en los casos en los que una de las partes hubiere alegado "error esencial" para una prueba pericial, pero no hubiere justificado el error dentro del término fijado por el tribunal arbitral, no será posible iniciar una acción de nulidad bajo esta causal ${ }^{34}$. Asimismo, se ha mencionado que si el tribunal arbitral solicita a

31. Proceso No. 17100-2017-00008, sentencia dictada por la Corte Provincial de Pichincha el 1 de septiembre de 2017: "Esta causal puede desglosarse en tres hechos que pueden causar la nulidad del laudo. Tomando en cuenta la redacción de la norma, el primero sería cuando no se hubiera convocado una prueba que fue solicitada por una de las partes; el segundo hecho es que no se haya notificado la convocatoria; $y$, el tercer hecho sería cuando luego de convocada no se hubiere practicado la prueba, a pesar de la existencia de hechos que deban justificarse. En este caso, las pruebas sí fueron convocadas y ordenadas, sin embargo no fueron practicadas por alguna razón imputable al Tribunal, hecho que deja a la parte en indefensión, ya que si no se practican las pruebas solicitadas, no puede fundamentar sus argumentos y pretensiones".

Véanse los siguientes procesos: proceso No. 17100-2017-00037, sentencia dictada por la Corte Provincial de Pichincha el 23 de noviembre de 2017; proceso No. 17100-2013-0081, sentencia dictada por la Corte Provincial de Pichincha el 7 de diciembre de 2014; proceso No. 171002018-00021, sentencia dictada por la Corte Provincial de Pichincha el 9 de enero de 2019; proceso No. 17100-2019-00008, sentencia dictada por la Corte Provincial de Pichincha el 28 de octubre de 2019; proceso No. 17100-2019-00001, sentencia dictada por la Corte Provincial de Pichincha el 2 de mayo de 2019.

32. Proceso No. 17100-2015-00002, sentencia dictada por la Corte Provincial de Pichincha el 14 de julio de 2015.

33. Proceso No. 17100-2017-00047, sentencia dictada por la Corte Provincial de Pichincha el 11 de abril de 2018; proceso No. 17100-2019-00001, sentencia Pichincha el 2 de mayo de 2019: "En consecuencia, la valoración del árbitro o tribunal arbitral, no se subsume al vicio de procedimiento contenido en el artículo 31 literal c) de la Ley de Arbitraje y Mediación, como ha cuestionado el accionante. Haciéndose hincapié en que no le corresponde a esta Autoridad realizar pronunciamiento respecto a la forma en que se realizó la prueba, o la forma en que el árbitro la analiza o valora al momento de resolver, corresponde a la autoridad pronunciarse, únicamente en caso de que la misma no se haya convocado o convocada no se la haya realizado"

34. Proceso No. 17100-2011-0028, sentencia dictada por la Corte Provincial de Pichincha el 15 de noviembre de 2011. 
las partes que justifiquen las razones por las que no se acompañó la prueba a la demanda o a la contestación a la demanda y las partes no lo hacen, no pueden invocar esta causal para anular el laudo ${ }^{35}$.

Finalmente, la jurisprudencia ha señalado que, si la accionante no especifica las pruebas que no se pudieron practicar, o no fundamenta los hechos que la prueba estaba dirigida a probar ${ }^{36}$, no procede la acción de nulidad.

En conclusión, el análisis realizado por los presidentes de las cortes provinciales es correcto, en la medida en que se debe realizar un análisis de la prueba solicitada por las partes, la prueba admitida y la prueba que fue efectivamente practicada durante el proceso. Consideramos acertado que los presidentes de las cortes provinciales no lo analicen.

\subsection{Causal d): que el laudo se refiera a cuestiones no sometidas al arbitraje o conceda más allá de lo reclamado}

Como ha sido mencionado anteriormente, la causal de la letra d) ha sido la más invocada por las partes al plantear una acción de nulidad y la que más veces ha sido aceptada por las presidencias de las cortes provinciales al momento de anular un laudo. A continuación presentamos un análisis sobre cómo esta causal ha sido interpretada.

El artículo 31 de la LAM prevé que se pueda iniciar una acción de nulidad cuando "el laudo se refiera a cuestiones no sometidas al arbitraje o conceda más allá de lo reclamado".

La Corte Provincial de Pichincha ha anulado laudos bajo esta causal en los siguientes casos:

a) Un tribunal arbitral declaró la nulidad relativa de oficio, pese que esta debía ser declarada a petición de parte y la parte correspondiente no la solicitón ${ }^{37}$.

35. Proceso No. 17100-2019-00005, sentencia dictada por la Corte Provincial de Pichincha el 14 de agosto de 2019.

36. Proceso No. 17100-2019-00008, sentencia dictada por la Corte Provincial de Pichincha el 28 de octubre de 2019.

37. Proceso No. 17100-2013-0116, sentencia de 2 de junio de 2015. 
b) Los daños y perjuicios establecidos en el laudo se fijaron sin considerar el cálculo del informe pericial ${ }^{38}$.

c) Un laudo se refirió a actos administrativos y, por lo tanto, a asuntos (a criterio del presidente de la Corte Provincial de Pichincha) no arbitrables, ya que los actos administrativos deberían ser impugnados mediante la interposición de recursos administrativos $\mathrm{y}$ acciones judiciales, mas no en procesos arbitrales.

De esta manera, en un primer caso, el presidente de la Corte Provincial de Pichincha determinó que el acto unilateral por el cual la Agencia de Regulación y Control de las Telecomunicaciones (ARCOTEL) solicitó a la empresa OTECEL S.A. el pago de una suma de dinero, tenía como antecedente las resoluciones emitidas por la Superintendencia de Telecomunicaciones (SUPERTEL) y la Ley Orgánica de Telecomunicaciones, y, por lo tanto, constituía un acto administrativo emitido dentro de la actividad jurídica de la administración. Al tratarse de una decisión unilateral efectuada en ejercicio de la función administrativa que producía efectos jurídicos individuales y directos, según el presidente de la Corte, no se trataría de una simple recaudación de valores impuestos contractualmente por los efectos de una cláusula penal, como alegó OTECEL S.A., sino que se trataría de un acto administrativo que solo podía ser impugnado mediante la interposición de recursos administrativos y acciones judiciales ${ }^{39}$. Por tal razón se verificaba la causal de la letra d) y el laudo debía ser anulado.

En un segundo caso, el presidente de la Corte Provincial de Pichincha determinó que la resolución No. 223 del gerente general de la CAE, que impuso una multa equivalente a 40 veces la tarifa correspondiente al 1\% que COTECNA cobró a la importación de AFABA por servicios prestados, sería un acto administrativo sancionatorio y no una multa contractual como alegó COTECNA en el proceso arbitral. Dicho acto administrativo habría ordenado el pago de una indemnización por los daños y perjuicios ocasionados al Estado por la importación realizada por AFABA. En consecuencia,

38. Proceso No. 17113, 2014, 1296, sentencia de 10 de octubre de 2014. En este caso, la Sala de lo Civil y mercantil de la Corte Provincial dejó sin efecto la decisión del presidente de la Corte Provincial y declaró la validez del laudo, considerando que el tribunal arbitral se alejó del cálculo establecido en el informe pericial, en aplicación del principio de la sana crítica.

39. Proceso 17100-2018-00006, sentencia de 2 de agosto de 2018. 
al igual que en el caso anterior, al tratarse de una declaración unilateral efectuada en ejercicio de la función administrativa que produce efectos jurídicos individuales de forma directa no podría ser sometida a arbitraje. El presidente de la Corte Provincial determinó que la imposición de una multa por parte de un funcionario público es la consecuencia del ejercicio de una potestad pública derivada del supuesto incumplimiento de un contrato y no puede someterse a la jurisdicción convencional las controversias no susceptibles de transacción. De esta manera, al verificarse la causal de la letra d) del artículo 41, el laudo debía ser anulado ${ }^{40}$.

d) Un tribunal arbitral resolvió sobre un asunto que no fue motivo de la litis arbitral, como resolver sobre la cesión de derechos litigiosos alegada por una de las partes, sin que en el contrato en disputa se hiciera referencia alguna a la cesión de los derechos litigiosos a favor de un beneficiario ${ }^{41}$.

e) Un laudo habría incurrido en un vicio de incongruencia extra petita cuando, pese a que la parte accionante solicitó que se extinga un registro de una deuda para el periodo comprendido entre los años 2000 y 2005, el tribunal arbitral al dictar el laudo consideró los períodos 2012 y $2016^{42}$.

f) Un tribunal arbitral resolvió algo distinto a la pretensión de la parte actora, pues la parte actora presentó la demanda para constituir en mora a la parte demandada y el tribunal arbitral ordenó el pago del canon de arrendamiento incumplido ${ }^{43}$.

g) Un tribunal arbitral ordenó el pago de una cantidad de dinero a uno de los socios de una compañía, sin que previamente hubiere ordenado la liquidación de la sociedad, como había solicitado la parte actora ${ }^{44}$.

Por su parte, en la provincia del Guayas ha declarado la nulidad de laudos arbitrales, con base en causal bajo análisis, en los siguientes casos:

40. Proceso 17100-2013-0042, sentencia de 16 de mayo de 2018.

41. Proceso No. 17100-2007-133, sentencia de 6 de marzo de 2008.

42. Proceso No. 17100-2018-00026, sentencia de 1 de febrero de 2019.

43. Proceso No. 17100-2018-00012, sentencia de 12 de abril de 2019.

44. Proceso No. 17100-2018-0032, sentencia de 13 de febrero de 2019. 
a) El árbitro único no analizó lo manifestado por la parte accionante sobre la prueba solicitada, por lo que esta no habría sido practicada ni valorada, lo que habría dejado en indefensión al actor y vulnerado el debido proceso ${ }^{45}$.

b) Un tribunal arbitral dictó un laudo sin resolver la totalidad de las pretensiones, lo cual configuraría un vicio de incongruencia ${ }^{46}$.

c) Un tribunal arbitral se pronunció sobre la validez de una escritura pública de poder general, sin que esta facultad hubiere estado prevista en la cláusula compromisoria y, por lo tanto, al hacerlo, se ha vulnerado el derecho constitucional de los intervinientes en la escritura pública de la referencia, incluido el notario público correspondiente. Esto implicaría la violación al derecho a ser juzgados por autoridad competente, con observancia de las reglas específicas de cada procedimiento, y sobre todo a ser escuchados en igualdad de condiciones, y poder presentar los descargos respectivos ${ }^{47}$.

d) Un tribunal arbitral acumuló dos tipos de responsabilidades respecto a una misma situación jurídica y entre las mismas personas a causa de una infracción contractual, sin que las partes hubieren acordado someter a arbitraje la responsabilidad civil por daños morales ${ }^{48}$.

e) Un laudo que incurrió en un error de cálculo en la parte dispositiva, sin que el tribunal considere un saldo sobre el monto del anticipo en disputa ${ }^{49}$.

Según la jurisprudencia existente, esta causal se habría verificado en los siguientes casos:

i) Cuando el laudo recae sobre materias que no fueron contempladas en el pacto arbitral; de conformidad con lo acordado voluntariamente por las partes, considerando los límites dentro de los cuales pueden actuar válidamente son señalados por ellas en el objeto de la cláusula compromisoria

45. Proceso No. 09100-2014-0166, sentencia de 9 de diciembre de 2014.

46. Proceso No. 09100-2016-00021, sentencia de 3 de agosto de 2016.

47. Proceso No. 09100-2018-00016, sentencia de 8 de agosto de 2018.

48. Proceso No. 09100-2019-00021, sentencia de 19 de agosto de 2019.

49. Proceso No. 09100-2019-00013, sentencia de 17 de septiembre de 2019. 
o pacto arbitral tomando en consideración el límite material del arbitraje (materia transigible); o ii) cuando el laudo recae sobre puntos no pedidos en la demanda o en su contestación, es decir, no se refiere a los hechos y a las pretensiones formuladas en la demanda, ni a las excepciones alegadas, de manera que no resulta concordante ni armónico con los extremos del proceso y, por ende, deviene en inconsonante o incongruente ${ }^{50}$.

La jurisprudencia también ha señalado que esta causal se verifica cuando el tribunal arbitral concedió a alguna de las partes más de lo solicitado (ultra petita), algo distinto a lo solicitado (extra petita) o cuando se haya omitido la resolución de una de las pretensiones o excepciones de las partes (infra petita $)^{51}$.

El examen que realizan los presidentes de las cortes provinciales para establecer si un laudo tiene un vicio de incongruencia consiste en comparar las pretensiones y excepciones de las partes con lo resuelto en el laudo. Es decir, es necesario realizar una "comparación entre el petitium de la demanda, las excepciones y reconvenciones presentadas, y lo resuelto en la sentencia" ${ }^{25}$.

50. Proceso No. 17100-2018-00027, sentencia de 6 de mayo de 2019: "La incongruencia se produce cuando la porción dispositiva del laudo ha incorrectamente considerado la dinámica entre pretensiones y excepciones respecto de su contenido y ha fallado sobre asuntos distintos o mayores a los restringidamente resultantes de la interacción de esas pretensiones o excepciones. La incongruencia es un error in procedendo que tiene tres aspectos: a) Cuando se otorga más de lo pedido (plus o ultra petita); b) Cuando se otorga algo distinto a lo pedido (extra petita); $y$, e) Cuando se deja de resolver sobre algo pedido (citra petita o infra petita). Entonces como instrumento de análisis, el defecto procesal de incongruencia debe resultar de la comparación entre la súplica de la demanda, la contestación y la parte dispositiva de la sentencia". Véanse los siguientes procesos: proceso No. 17100-2018-00026, sentencia de 1 de febrero de 2019; proceso No. 17100-2018-00016, sentencia de 21 de noviembre de 2018; proceso No. 17100-2018-00012, sentencia de 12 de abril de 2019; proceso No. 17100-2018-00009, sentencia de 1 de octubre de 2018; proceso No. 17100-2018-00038, sentencia de 16 de abril de 2019;

51. Proceso No. 17100-2018-00006, sentencia de 2 de agosto de 2018; proceso No. 17100-20140059, sentencia de 7 de enero de 2016; proceso No. 17100-2018-00029, sentencia de 3 de diciembre de 2018;

52. Proceso No. 17100-2014-0078, sentencia de 15 de julio de 2016.

Véanse los siguientes procesos: proceso No. 17100-2015-00002, sentencia de 14 de julio de 2015; proceso No. 17100-2015-00003, sentencia de 17 de noviembre de 2015; proceso No. 17100-201500007, sentencia de 9 de agosto de 2016; proceso No. 17100-2015-00016, sentencia de 3 agosto de 2016; proceso No. 17100-2016-00002, sentencia de 14 de noviembre de 2016; proceso No. 17113-2014-1296, sentencia de 10 de septiembre de 2014; proceso No. 17100-2017-00005, sentencia de 19 de agosto de 2017; proceso No. 17100-2017-00006, sentencia de 9 de noviembre de 2015; proceso No. 17100-2017-00039, sentencia de 12 de abril de 2018; proceso No. 171002017-00017, sentencia de 31 de agosto de 2017; proceso No. 17100-2017-00017, sentencia de 31 de agosto de 2017; proceso No. 17100-2017-00030, sentencia de 8 de noviembre de 2017; proceso No. 17100-2017-00024, sentencia de 17 de noviembre de 2017; proceso No. 17100-2017-00021, 
La jurisprudencia de las cortes provinciales incurre, a nuestro criterio, en tres errores:

a. Los jueces no tienen competencia para resolver asuntos sustantivos ni entrar a analizar asuntos de competencia exclusiva de los árbitros, pues la acción de nulidad ha sido universalmente concebida para verificar errores adjetivos o in procedendo exclusivamente. En la mayoría de los casos analizados, los jueces se han extralimitado al analizar los méritos de la causa, llevándolos a analizar la transigibilidad de la controversia, valorar nuevamente las pruebas o interpretar un contrato. Especial mención merecen las decisiones sobre la inarbitrabilidad de los actos administrativos que no tienen relación genuina con la causal de incongruencias ultra y extra petita. La arbitrabilidad y transigibilidad de la materia sometida a arbitraje son asuntos sustantivos (no adjetivos) en Ecuador, definidos especialmente en la Constitución ecuatoriana y en el Código Civil (i.e. contrato de transacción). Por otro lado, la arbitrabilidad de la disputa (i.e. competencia ratione materiae) es un asunto que debe analizar privativamente el árbitro en la audiencia de sustanciación, sin que las cortes provinciales puedan asumir dicha tarea so pretexto de examinar una causal que no tiene relación con la arbitrabilidad de la controversia, como ha aclarado tajantemente la Corte Constitucional ${ }^{53}$.

sentencia de 17 de noviembre de 2017; proceso No. 17100-2017; proceso No.17100-2017000018, sentencia de 11 de septiembre de 2017; proceso No. 17100-2015-00014, sentencia de 3 de marzo de 2016; proceso No. 17100-2015-0001, sentencia de 13 de enero de 2016; proceso No. 17100-2016-0003, sentencia de 10 de noviembre de 2017; proceso No. 17100-2017-00036, sentencia de 27 de julio de 2017; proceso No. 17100-2018-00006, sentencia de 2 de agosto de 2018; proceso No. 17100-2014-0038, sentencia de 14 de noviembre de 2014; proceso No. 171002014-0038, sentencia de 14 de noviembre de 2014; proceso No. 17100-2014-0010, sentencia de 1 de agosto de 2015; proceso No. 17100-2014-0010, sentencia de 7 de agosto de 2015; proceso No. 17100-2014-0070, sentencia de 28 de junio de 2016; proceso No. 17100-2014-0059, sentencia de 7 de enero de 2016; proceso No. 17100-2017-00047, sentencia de 15 de agosto de 2014; proceso No. 17100-2018-00030, sentencia de 3 de diciembre de 2018; proceso No. 17100-201800029, sentencia de 3 de diciembre de 2018; proceso No. 17100-2018-00032, sentencia de 13 de febrero de 2019; proceso No. 17100-2019-0008, sentencia de 13 de febrero de 2019; proceso No. 09100-2016-00021, sentencia de 3 de agosto de 2016; proceso 17100-2014-0071, sentencia de 24 de agosto de 2015.

53. Sentencia No. 1737-16-EP/21 de 21 de julio de 2021: "Es decir, al que le correspondía pronunciarse sobre el convenio arbitral es al tribunal arbitral, mas no a la justicia ordinaria, ya que, según el principio kompetenz kompetenz, el tribunal arbitral es el primero en resolver sobre su competencia. Por lo que, el análisis sobre la suficiencia y validez de la cláusula arbitral y, por ende, la determinación de si la cláusula arbitral era o no patológica o si el tribunal arbitral era competente o no para conocer la controversia, es un asunto que no le correspondía a la justicia ordinaria". 
Incluso en el escenario de que un laudo se refiera a asuntos no transigibles, el laudo no sería anulable bajo esta causal, pues las incongruencias extra y ultra petita no tienen relación con el alcance del convenio arbitral, sino con el cotejo procesal entre las pretensiones y excepciones de las partes, y lo resuelto por el tribunal. En otros países este tipo de escenarios podrían llevar a la nulidad de un laudo bajo las causales de inarbitrabilidad o de violación al orden público, las cuales, en Ecuador, no existen.

b. Los presidentes de las cortes provinciales están permitiendo que en la causal (d) se cuelen varias alegaciones y defensas que no tienen conexión con las incongruencias extra y ultra petita. En general, los errores de derecho o de valoración de la prueba de los árbitros, que son asuntos sustantivos en Ecuador, no pueden ser admitidos bajo una causal que está concebida para otro tipo de incongruencias. Lo mencionado es relevante si consideramos que aproximadamente la mitad de las sentencias analizadas que se sustentan en esta causal no tienen realmente relación con incongruencias extra y ultra petita. Si consideramos que (i) esta es la causal más invocada en Ecuador, (ii) la mitad de los casos se refieren a asuntos "misceláneos" inconexos con esta causal y (iii) existen otras causales que han sido aceptadas por ciertas cortes ${ }^{54}$, el resultado matemático es preocupante, pues la causal "misceláneos" se estaría erigiendo como el principal motivo para anular laudos, sin estar permitida en la ley.

c. Finalmente, la causal (d) no incluye a la incongruencia infra petita, no obstante lo cual existen laudos anulados por esta incongruencia. No sugerimos que esta incongruencia no sea relevante, sino que las causales de nulidad son taxativas y no pueden ser ampliadas mediante jurisprudencia.

Es indispensable que los presidentes de las cortes provinciales revean su actuación respecto de esta causal, mediante un análisis apegado a derecho que no genere abusos de derecho de los litigantes, extralimitaciones de funciones de los jueces y una desnaturalización de la acción de nulidad.

54. N. 6.6. 


\subsection{Causal e): cuando se hayan violado los procedimientos previstos por la ley o por las partes para designar árbitros o constituir el tribunal arbitral}

Finalmente, la última causal que establece la LAM para que una acción de nulidad sea procedente es la relacionada a la indebida constitución del tribunal arbitral: "cuando se hayan violado los procedimientos previstos por esta Ley o por las partes para designar árbitros o constituir el tribunal arbitral."

La causal de indebida constitución del tribunal arbitral ha sido recurrentemente invocada por los accionantes, en al menos 40 ocasiones.

Para resolver la procedencia de esta causal, los presidentes de las cortes provinciales han analizado el proceso de selección, sorteo y designación de los árbitros con el objetivo de verificar si estas etapas cumplieron con el procedimiento establecido en la LAM o en los respectivos convenios arbitrales.

La jurisprudencia ha establecido que para que la constitución del tribunal sea legal es necesario que se cumpla con el procedimiento establecido en los artículos 16 y 17 de la LAM. Por ejemplo, la Corte Provincial de Pichincha ha considerado que la posesión de un tribunal arbitral en un arbitraje administrado debe realizarse ante el presidente del centro de arbitraje y no ante su delegado ${ }^{55}$.

En el caso de arbitrajes ad-hoc, la jurisprudencia ha establecido que el proceso de selección, designación y posesión del tribunal arbitral deberá seguir lo dispuesto por el artículo 17 de la LAM o el acuerdo de las partes. Así, la Corte Provincial de Guayas ha declarado la nulidad de un laudo cuyo tribunal arbitral fue designado por el Centro de Arbitraje y Conciliación de la Cámara de Comercio de Guayaquil, pese a que el convenio arbitral establecía un proceso ad-hoc ${ }^{56}$.

55. Proceso 17113-2014-1359, sentencia dictada por la Corte Provincial de Pichincha el 15 de agosto de 2016.

56. Proceso 09100-2017-00032, sentencia dictada por la Corte Provincial de Pichincha el 24 de julio de 2018: "En tal virtud y sin profundizar en las demás alegaciones que la accionante ha establecido en su acción, a criterio de este Juzgador habiéndose respetado las garantías al debido proceso, al considerar que se ha adecuado entre las pretensiones de la parte accionante la causal e) del Art. 31 de la Ley de Arbitraje y Mediación, lo que conlleva a expresar que desde 
En conclusión, las cortes provinciales aceptan la causal prevista en la letra e) de la LAM únicamente en los casos en los que existe una manifiesta violación de los procedimientos para constituir el tribunal. Esta causal ha sido adecuadamente aplicada por las cortes provinciales, existiendo únicamente los dos casos comentados en los que la causal prosperó.

\section{6. ¿Se ha declarado la nulidad de un laudo arbitral por causales no contempladas en el artículo 31 de la LAM?}

En 8 casos gestionados en la Provincia de Pichincha, se invocaron las siguientes causales no contempladas en el artículo 31 de la LAM: (i) vulneración al derecho de petición; (ii) desistimiento; (iii) falta de motivación del laudo; (iv) el derecho a ser juzgado por un juez competente e imparcial; (v) artículos 32 y 33 del Tratado de Creación del Tribunal de Justicia de la Comunidad Andina respecto a la interpretación prejudicial y el artículo 123 del Estatuto del Tribunal de Justicia de la Comunidad Andina sobre la consulta obligatoria de normas; (vi) falta de motivación; y (vii) el laudo emitido fuera del plazo $^{57}$.

Afortunadamente, en ninguno de los casos en los que se invocó una causal distinta a las previstas en el artículo 31 de la LAM se aceptó la acción de nulidad propuesta. Los argumentos del presidente de la Corte Provincial de Pichincha para rechazar la acción de nulidad en estos casos fueron los siguientes:

a) La acción de nulidad pretende corregir los vicios de procedimiento, así como extra y ultra petita en los que pueda incurrir el tribunal de arbitraje y, por lo tanto, está supeditada exclusivamente a las causales previstas en el artículo 31 de la LAM. La acción de

un inicio el Tribunal Arbitral estuvo mal conformado, pues no se los designó como se había pactado en el Art. 14 de los contratos de reaseguros de Cuota Aparte y Primer excedente, lo que deviene como procedente la acción planteada".

57. Véanse los siguientes procesos: Proceso No. 09100-2014-0170, sentencia dictada por la Corte Provincial de Guayas el 19 de diciembre de 2014; proceso No. 17100-2017-00026, sentencia dictada por la Corte Provincial de Pichincha el 21 de septiembre de 2017; proceso No. 171002018-00016, sentencia dictada por la Corte Provincial de Pichincha el 21 de noviembre de 2018; proceso No. 17100-2018-00037, sentencia dictada por la Corte Provincial de Pichincha el 9 de abril de 2019; proceso No. 17100-2019-00005, sentencia dictada por la Corte Provincial de Pichincha el 14 de agosto de 2019; y proceso No. 17100-2019-00004, sentencia dictada por la Corte Provincial de Pichincha el 12 de septiembre de 2019. 
nulidad no es el mecanismo que permita examinar cuestiones fuera de las referidas en el mencionado artículo ${ }^{58}$.

b) El control constitucional de los laudos arbitrales debe realizarse mediante una acción extraordinaria de protección ${ }^{59}$.

c) La supuesta vulneración al ordenamiento jurídico andino no configura una de las causales previstas en el artículo 31 de la $\mathrm{LAM}^{60}$.

d) Es ilógico que se pida la nulidad parcial del laudo arbitral por indebida motivación, ya que esta garantía constitucional incide en la totalidad de la sentencia y no solo en la parte que le beneficia al actor ${ }^{61}$.

e) La falta de motivación del laudo no está prevista como una causal de nulidad en el artículo 31 de la LAM y para determinar si el laudo es nulo por este vicio basta contrastar las pretensiones del actor en la demanda arbitral con lo resuelto por el tribunal de arbitraje ${ }^{62}$.

f) Se verificó que el árbitro no había excedido el plazo para la emisión del laudo ${ }^{63}$.

Por otro lado, en 12 de los casos analizados de la provincia del Guayas, se invocaron las siguientes causales: (i) transgresión al derecho de petición; (ii) vulneración al derecho a la defensa; (iii) falta de motivación del laudo; (iv) vulneración al debido proceso; (vi) violación al debido proceso...". Por favor, eliminar el número vi y que conste lo siguiente: "en 12 de los casos analizados de la provincia del Guayas, se invocaron las siguientes causales: (i) transgresión al derecho de petición; (ii) vulneración al derecho a la defensa; (iii) falta de motivación del laudo; (iv) vulneración al debido proceso; y (v) vulneración al derecho de contradicción y defensa. En ninguno de ellos se declaró la nulidad

58. Proceso No. 17100-2018-00037, sentencia dictada por la Corte Provincial de Pichincha el 9 de abril de 2019.

59. Proceso No. 17100-2018-00037, sentencia dictada por la Corte Provincial de Pichincha el 9 de abril de 2019.

60. Proceso No. 17100-2018-00037, sentencia dictada por la Corte Provincial de Pichincha el 9 de abril de 2019.

61. Proceso No. 17100-2018-00037, sentencia dictada por la Corte Provincial de Pichincha el 9 de abril de 2019.

62. Proceso No. 17100-2018-00016, sentencia dictada por la Corte Provincial de Pichincha el 21 de noviembre de 2018.

63. Proceso No. 17100-2019-00004, sentencia dictada por la Corte Provincial de Pichincha el 12 de septiembre de 2019. 
del laudo ${ }^{64}$. Los argumentos del presidente de la Corte Provincial de Guayas en estos casos fueron los siguientes:

(a) El tribunal arbitral al emitir el laudo resolvió la petición de la parte actora y la declaró improcedente, por lo que no existe violación al derecho de petición ni de defensa ${ }^{65}$.

(b) El laudo no contiene "motivación absurda", puesto que la información que brindó una de las partes al Tribunal, que se refería a otro caso, fue empleada como mecanismo de defensa en el caso bajo conocimiento de los árbitros y eso, a criterio del presidente de la Corte Provincial del Guayas no constituía un razonamiento carente de lógica ${ }^{66}$.

(c) El tribunal arbitral se pronunció sobre temas que fueron puestos a su conocimiento sin exceder su competencia y el accionante fundamentó la nulidad en la causal de "valoración de la prueba", lo cual no constituye una causal según el artículo 31 de la $\mathrm{LAM}^{67}$.

(d) La falta de motivación de la providencia de prórroga del plazo para la emisión del laudo arbitral, que fue el argumento invocado por una de las partes como falta de motivación, no habría sido impugnada por ninguna de las partes, además de

64. Véanse los siguientes procesos: Proceso No. 09100-2014-0170, sentencia dictada por la Corte Provincial de Guayas el 19 de diciembre de 2014; proceso No. 09100-2014-0172, sentencia dictada por la Corte Provincial de Guayas el 24 de diciembre de 2014; proceso No. 09100-201500033, sentencia dictada por la Corte Provincial de Guayas el 20 de noviembre de 2015; proceso No. 09100-2015-0002, sentencia dictada por la Corte Provincial de Guayas el 19 de diciembre de 2014; proceso No. 09100-2015-0003, sentencia dictada por la Corte Provincial de Guayas el 27 de marzo de 2015; proceso No. 09100-2016-00021, sentencia dictada por la Corte Provincial de Guayas el 19 de diciembre de 2014; proceso No. 09100-2016-0001, sentencia dictada por la Corte Provincial de Guayas el 4 de abril de 2016; proceso No. 09100-2017-00025, sentencia dictada por la Corte Provincial de Guayas el 13 de noviembre de 2017; proceso No. 091002017-00028, sentencia dictada por la Corte Provincial de Guayas el 13 de noviembre de 2017; proceso No. 09100-2017-00031, sentencia dictada por la Corte Provincial de Guayas el 16 de noviembre de 2017; proceso No. 09100-2017-00029, sentencia dictada por la Corte Provincial de Guayas el 22 de noviembre de 2017; y proceso No. 09100-2019-00021, sentencia dictada por la Corte Provincial de Guayas el 19 de agosto de 2019.

65. Proceso No. 09100-2014-0170, sentencia dictada por la Corte Provincial de Guayas el 19 de diciembre de 2014.

66. Proceso No. 09100-2014-0172, sentencia dictada por la Corte Provincial de Pichincha el 24 de diciembre de 2014.

67. Proceso No. 09100-2015-00033, sentencia dictada por la Corte Provincial de Pichincha el 20 de noviembre de 2011. 
que es perfectamente posible prorrogar la duración del proceso arbitral $^{68}$.

(e) El laudo no sufre de motivación absurda si la demanda se refirió a la violación de la obligación de mantener el arbitraje confidencial, ya que la confidencialidad no es absoluta y no puede estar por encima del derecho a la defensa ${ }^{69}$.

(f) Existe un vicio de incongruencia cuando el tribunal arbitral dicta un laudo sin resolver la totalidad de las pretensiones ${ }^{70}$.

(g) Existe una afectación al debido proceso y se afecta directamente a la parte que quiere interponer un recurso de nulidad del laudo dentro del término previsto en el artículo 3 de la LAM, si la secretaria del tribunal arbitral sienta la razón de la ejecutoría del laudo arbitral sin esperar que transcurran los días previstos en la ley para la ejecutoría y sin esperar la resolución del recurso horizontal de aclaración y ampliación ${ }^{71}$.

Finalmente, en dos de los casos analizados de la Provincia del Azuay en los que se invocaron la violación al artículo 76 de la Constitución y la falta de motivación del laudo como causales para la anulación del laudo, en ninguno de ellos se declaró la nulidad del laudo, ni se aceptaron las causales invocadas ${ }^{72}$. El razonamiento del presidente de dicha corte provincial fue que en uno de los casos, el laudo estaba debidamente motivado y el tribunal arbitral no concedió más allá de lo reclamado, ni se pronunció sobre asuntos no sometidos a arbitraje. En el otro caso, el accionante no presentó una demanda, sino que únicamente interpuso un recurso de nulidad, lo cual no es posible en el ordenamiento jurídico ecuatoriano.

68. Proceso No. 09100-2015-0002, sentencia dictada por la Corte Provincial de Guayas el 7 de abril de 2015.

69. Proceso No. 09100-2015-0003, sentencia d dictada por la Corte Provincial de Guayas el 27 de marzo de 2015.

70. Proceso No. 09100-2016-00021, sentencia dictada por la Corte Provincial de Guayas el 3 de agosto de 2016.

71. Véanse los procesos No. 09100-2017-00025, sentencia dictada por la Corte Provincial de Guayas el 13 de noviembre de 2017; proceso No. 09100-2017-00028, sentencia dictada por la Corte Guayas el 13 de noviembre de 2017; y proceso No. 09100-2017-00031, sentencia dictada por la Corte Provincial de Pichincha el de 16 de noviembre de 2017.

72. Véanse los siguientes procesos: proceso No. 01100-2014-0017, sentencia dictada por la Corte Provincial de Azuay el 20 de mayo de 2015; y proceso No. 01100-2017-00004G, sentencia dictada por la Corte Provincial de Azuay el 8 de febrero de 2017. 


\section{Conclusiones}

Tomando en consideración las acciones de nulidad recopiladas y analizadas, los fundamentos de cada causal y los criterios que han sido empleados para resolver las acciones de nulidad de laudos arbitrales por los presidentes de las cortes provinciales, podemos emitir las siguientes conclusiones a nuestro estudio:

Primero, el aumento en el número de acciones de nulidad propuestas parecería tener relación con el incremento proporcional en el número de causas arbitrales que denota una clara tendencia creciente.

Segundo, el estudio realizado evidencia que en el 75\% de casos la parte vencida del arbitraje es quien interpone la acción de nulidad en contra del laudo que no le fue favorable, buscando impugnar la decisión del tribunal y en algunos casos tratando de entorpecer la ejecución del laudo.

Tercero, a nivel nacional, las causales de nulidad más invocadas son las contempladas en las letras c) y d) del artículo 31 de la LAM. Sin embargo, existe un preocupante número de casos en que se alegan causales que no están previstas en la LAM y que se han disfrazado bajo la causal d).

Cuarto, la jurisprudencia ha desarrollado ciertos presupuestos que deben verificarse para que proceda cada causal Así, con excepción de la causal d), el test definido por las presidencias de las cortes provinciales es adecuado-aunque existan las extralimitaciones comentadas-, puesto que se basa en el estudio del expediente para verificar: (i) si la citación se ha realizado en legal y debida forma y si el demandado ha comparecido o no al proceso; (ii) si existe una providencia que no haya sido notificada y que haya afectado el derecho a la defensa de las partes; (iii) si se ha notificado a la práctica de las pruebas y si las pruebas anunciadas y admitidas por el tribunal fueron practicadas; y (iv) si se constituyó al tribunal arbitral en apego a la voluntad de las partes y a la ley.

Quinto, el análisis de la causal d) ha generado problemas en la práctica puesto que ha sido empleada para que los presidentes de las 
cortes provinciales se pronuncien sobre el fondo de la controversia. En estos casos se ha evidenciado una intromisión judicial en los méritos de la controversia que son de competencia exclusiva del tribunal arbitral.

Finalmente, en sexto lugar, existe un número considerable de casos en los que se han iniciado acciones de nulidad por causas no previstas en la LAM. Afortunadamente, se observa una tendencia de los presidentes de las cortes provinciales de no aceptar acciones de nulidad que no se encuentren previstas expresamente en la LAM. 